\title{
Patient mental attitude: a systematic review
}

\author{
Eri H. Jubhari ${ }^{*}$, Kezia Rachellea ${ }^{2 *}$
}

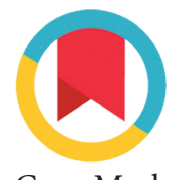

Abstract

Objective: To review the classifications of denture patient's mental attitude in order to expand reader's knowledge and help practitioners to confront their patient.

Methods: Electronic search in internet to find articles which were published in last 20 years with keywords "patient mental attitude" and "house classification". Articles were then selected by reviewing the title and abstract.
Results: Based on data search, there are eight journal articles that suitable with the inclusion criteria.

Conclusion: It is important for dentists to recognize patient's mental attitude before patient's general condition to help dentist to communicate and deal with patient along their mental attitude, in order to create a bond of trust between patient and practitioner, facilitate the treatment procedure and make a better treatment result.
${ }^{1}$ Department of Prosthodontic, Faculty of Dentistry, Hasanuddin University, Makassar, Indonesia ${ }^{2}$ Department of Oral and Maxillofacial Surgery, Dental Research Institute, School of Dentistry, Seoul National University, Seoul, South Korea
"Correspondence to: Kezia Rachellea, Eri H. Jubhari, Department of Prosthodontic, Faculty of Dentistry, Hasanuddin University, Makassar, Indonesia keziarachelleamustakim@gmail.com; erihjubhari@gmail.com

Received: 24 June 2018 Revised: 26 June 2018 Accepted: 19 July 2018 Available Online: 1 August 2020

Keywords: Denture patient, House classification, Mental attitude, Prosthodontic treatment

Cite this Article: Jubhari EH, Rachellea K. 2020. Patient mental attitude: a systematic review. Journal of Dentomaxillofacial Science 5(2): 69-73. DOI: $10.15562 / j \mathrm{dmfs} . v 5 \mathrm{i} 2.754$

\section{Introduction}

Tooth loss is an incident that can occur in all age groups, both children and elderly. Incidence of tooth loss does impact to physiologic form of ridge, masticatory function, speech, esthetic, quality of life, and individual psychology. Studies have shown that through prosthodontic treatment, quality of life of dentate patient could be improved. ${ }^{1}$

In prosthodontic treatment, a dentist should not only examine the clinical condition but also psychological condition of patient, so the treatment could work well. De Van stated that we should meet the mind of patient before we meet the mouth of patient. This statement emphasizes the importance of understanding patient's mental attitude due to its effect to treatment procedure and the result. ${ }^{1,2}$

Every dental patient has a different mental attitude. Thus, In 1950, House devised the classification of denture patient's mental attitude to make it easier for dentist to recognize the psychological condition of patient, treatment planning, and how to communicate with patient based on their mental attitude. However, based on literature search, it stated that House wasn't the first person to classify patient's mental attitude. House's contribution seems to be an expansion of classifciation and popularization of system. ${ }^{3,4}$

This review will discuss about classification system of denture patient's mental attitude which was devised by House and other authors, in order to expand knowledge of reader to help in recognizing dental patient's mental attitude and how to deal with it.

\section{Methods}

Electronic search in internet was performed to find articles which were related to patient's mental attitude by reviewing the title and abstract.

Inclusion criteria: Articles in English, published in last 20 years, article on patient's mental attitude and House classification.

\section{Results}

Based on data search, eight journal articles were obtained by using "patient's mental attitude" and "House classification" keywords.

\section{Discussion Patient's Mental Attitude}

Achievement of prosthodontic treatment is determined by various factors, one of which is patient psychological condition, including; patient's readiness and their mental attitude to denture, patient's attitude and relation with dentist, knowledge and ability of patient to adapt to denture, and patient's trait. Jamieson stated that "fitting the personality of the aged patient is often more difficult than fitting the denture to the mouth". Recognizing the personality and mental attitude of patient is important for dentist to facilitate the treatment. ${ }^{2}$

\section{House Classification}

In 1950, House who contributed to science and prosthodontic's art development, devised a classification system of patient's psychological response to 
condition of being edentulous and denture. House classified this system into four types: philosophical mind, exacting mind, hysterical mind, and indifferent mind. ${ }^{4}$

\section{Philosophical mind}

This type of patient rationale, sensible, calm, and indulgent in every situation. This type will look forward for denture and is willing to listen to dentist's suggestion related to diagnosis and treatment. This type would follow dentist's suggestion about convert the old denture to a new one.,

\section{Exacting mind}

This type has similar characteristic to philosophical mind, yet the dentist need more attempts, patience, and attention to patient of this type. This type is methodist, precise, strict, and often make excessive demand. The patient may be in poor health condition and desperately need for treatment, still they are not willing to accept dentist's suggestion on extract the untreatable teeth and wear a denture. The patient with history of dental treatment dissatisfaction often doubt dentist's ability to design a denture that can work functionally and aesthetically. Moreover, this patient often want a guarantee of the treatment and demand more with no additional fee. However, once this patient satisfy with the treatment, this patient can be clinician's greatest supporter. ${ }^{2,4}$

\section{Hysterical mind}

This type is emotionally unstable, easily happy and easily anxious. This type have negative attitude, lack of maintaining their oral health, dentophobic, sometimes exacting but with unfounded complaint, lack of effort to adapt with denture, and have unrealistic expectation. Although they try to fit with denture, they often fail to wear because they think this denture will appear and function as natural teeth. The prognosis of treatment in this patient is poor. ${ }^{2,4}$

\section{Indifferent mind}

This patient is aphatetic, uninterested, and lack of motivation. This patient is more likely not concern about their appearance and not motivated to enjoy their meal. They can survive without denture. This patient do not concern to the instruction, no effort to cooperate with clinician, and more likely to blame dentist regarding a poor oral health of patient. The prognosis of this patient is doubtful or bad.

House classification was designed to help clinician anticipate patient's various responses to specific clinical procedure. However, reevaluation to this classification is needed regarding patients in isolation. House didn't put much attention to how the patient would response determined by treatment and dentist's attitude. ${ }^{2}$

According to Gamer et al. ${ }^{4}$ who cited House, ideal dental patient type was described, who characterized ideal dental patient as compliant, sophisticated, and responsive. Futhermore, who described four traits which characterized ideal patient's response, including realizes prosthetic treatment need, wants the prosthesis, accepts the denture, attempts to use prosthesis. Refer to Gamer et al, ideal patient ${ }^{6}$ suit House's philosophical type. ${ }^{4}$

\section{Winkler Classification}

Winkler proposed several patient categories; i.e. ${ }^{2}$

\section{The Hardy Elderly}

This type is physically and psychologically ready, active in social and professional life, and easily adapt to age change. ${ }^{2}$

\section{The Senile Aged Syndrome}

This type is physically and emotionally poor, and described as disable, have a chronic disease, infirm and truly aged. They can't cope with daily stress and prone to illness. ${ }^{2}$

\section{The Satisfied Old Denture Wearer}

This type is satisfied with the old denture despite the severe problem. They have adapted and happy with their old denture. ${ }^{2}$

\section{Geriatric Patient who doesn't Want Denture}

This type is elderly patient who has been living with no teeth for years and doesn't have any desire to wear full denture and lack of motivation. ${ }^{2}$

The last two categories have poor prognosis if the patient is insisted to receive the treatment.

\section{Gamer Classification}

In 2003, Simon Gamer et al presented the expansion of House classification including dentist's attitude as defining factor of patient's attitude. Gamer classification is based on two factors, i.e: patient's engagement level to dentist and treatment procedure in a continuum from totally engaged $(++++)$ to disengaged $(+)$. Patient's willingness level to trust dentist along a continuum from wilingness to submit to dentist's recommendation without second thought $(++++)$ to intense reluctance to do anything the dentist recommends $(+) .^{2}$

\section{Ideal Patient}

This type is similar to House's phylosophical type who involve $(+++)$ and trust dentist $(+++)$. They are not scored ++++ for these two categories due to maturity in balancing healthy life. It's normal for these patients to have doubt and questions. They 
deserve an explanation about professional dental treatment to understand the situation and can make a decision related to treatment. Therefore, ideal patient tend to be very critical or accept dentist's recommendation. ${ }^{2}$

\section{Submitter Patient}

Submitter patient are scored ++++ for involvement and ++++ for willingness to trust dentist. They do not discriminate and tend to idealize the dentist. This causes submitter do not have capacity to provide pure informed consent because they submit everything to dentist's skill and therefore this patient can't be an active partner in the treatment. ${ }^{2}$

\section{Reluctant Patient}

They are scored ++ for the involvement and ++ for willingness to trust dentist. They tend to doubt the dentist and are sceptical of treatment plan. ${ }^{2}$

\section{Indifferent Patient}

It's similar to House's indifferent mind patient, they are scored + for involvement and + for willingness to trust dentist. They are often forced to come to dentist by their relative and family. They have a very minimal involvement and very indifferent to dentist. $^{2}$

\section{Resistant Patient}

This type is similar to House's exacting mind. They are sceptical of dentist's figure as individual and of being helped by anyone under any circumtances. They are very involved with dentist but in a reverse way, rather than depend on dentist, they tend to defy the dentist. They trust the dentist the way indifferent type does. ${ }^{2}$

Classification of other patient's mental attitude; sharry classification TOLBUDS: patients who could tolerate prosthesis backwards, upside down or sideways, TOLAD: patients who could tolerate prosthesis with some degree of adjustment, TOLN: patient who could tolerate nothing. ${ }^{3}$

Blum classification; reasonable/Realistic: Well educated patients, are relaxed, and trust the physician with diagnosis and treatment plan, unreasonable/ Unrealistic: Less educated patients, have low income, overcritical, oversensitive, anxious, and do not trust the physician. ${ }^{3,5}$

Patient also can be classified as: cooperative: These patient are capable/not capable to know their need of denture but they are open-minded and receive any suggestion they were given. Treatment procedure can be explained wih less effort and they can be very cooperative. Apprehensive: Although this patient recognize their need of denture, however they have some problems that can't be solved through ordinary explanation. There are five types of apprehensive patient, i.e: anxious: This patient is anxious and disturbed by uncertainties of wearing denture. They always put themselves in a neurotic state. Frightened: They have an unfavourable fear about denture. Obsessive or exacting: they are naturally exacting. They decide their desire and tend to tell the dentist about how to proceed. They have to be handled firmly and tactfully. Chronic complainers: this patient is habitually fault finding and dissatisfied. Appreciating the corporation and incorporating as many of their ideas as possible with good denture construction is the best way to handle them. Self-conscious: They center chiefly on appearance. The best way to treat this patient is to give them attention constantly and permit participation as far as feasible in order to establish some responsibility in the result. Uncooperative: They do not feel the need of denture even though they really need it. Their general attitude is negative. ${ }^{2}$

\section{Association of sex, age, and educational level to mental attitude}

According to study that was conducted by Choudhary et al. ${ }^{1}$ they find that women tend to be exacting while men show indifferent attitude in a procedure of full denture treatment. Dental anxiety scale of female is higher than male. Association of female's choleric personality to psycosomatic preassure, and believe that happiness is related to social support, marriage, career, and religion that play the role in general and mental health. About female as an individual who care more about their appearance and more discipline to apply a healthy life behaviour. This is the main reason why women tend to visit dentist more than men. Futhermore, it is said that changes that affect someone's appearance like hair loss and face height, wrinkles, teeth appearance, and tooth loss tend to give more impact to women rather than men. Women often tend to give their opinion about treatment rathen than men. ${ }^{1}$

Patient aged 45 - 54 show exacting trait, while $\geq 65$ show hysterical trait compared to other age group. That can be caused by functional decrease of seniors aged $\geq 65$ including hearing function, visional fuction, and senses that psychologically implicate their attitude and personality. ${ }^{1}$

Patient who is educationally poor tend to be indifferent, while patient who is graduated from high school tend to be exacting than university graduate. This show educational level associate with satisfy and acceptance of full denture due to their inability to assess the condition correctly. ${ }^{1}$

\section{Doctor's behaviour}

A warm relation should be started with greeting before initial interview. This can be accomplished 
through emphaty, non verbal and verbal communication, some doctors have these communication skill intuitively while others have to acquire them over time.

Shaking hand with patient is an informative process. Dead fish handshake might indicate noncooperative patient without much interest. Vice like grip might indicate the patient feels anxious and attempt to give an impression to dentist that he can wear denture or try to prove that dentist can't do good job to him. Patient who gives a normal and firm handshake can indicate the patient is easy to get along with. ${ }^{4}$

Patient's mouth opening can indicate patient's behaviour to dental treatment. A success dentist is also a success teacher. They motivate patient to receive dental treatment as good as it can through observing the basic motive to push the patient in seeking a dental treatment. The teacher-like dentist prepare "lesson" for patient in one structure. They center the attention and action in giving patient an information and emphasizing the importance of information related to dental treatment. If patient is resentful and doubt the dentist, it can affect the patient's feeling to denture. This can be a rejection to denture. A dentist has to put an attempt in learning, understanding, and giving best attitude and action to patient related to treatment. A dentist should be able to see the effect of their attitude or action as stimulus to patient's behaviour during the treatment. A dentist also should be a good listener for patient by let the patient reveal their complaint and wish. Futhermore, there are seven traits a dentist should have to achieve a succesful treatment, including: friendly, be a good listener, avoid the argument, wisely criticize, don't be selfish, remember the name and face, be interested in others. In a study about the effect of dental appearance to personal characteristic appraisement, subjects with less dental problem, are socially more competent, intellectualy superior and psychologically have better adaptation. ${ }^{3}$

\section{Patient's satisfaction and expectation to denture}

A white clean teeth has become more realistic as a people's standard for ideal dental appearance. Therefore, various attempts are made to create a restoration, as natural as possible, and various prosthodontic treatments like full denture, partial denture, and implant began to emerge. Society often assume implant as the only solution for their edentuous condition due to its natural teeth like appearance, however they don't get the information entirely. ${ }^{6}$

Although mostly patient assume implant as the best denture, however partial denture also still become a main source of mastication and esthetic rehabilittation, due to its affordable price, especially for developing country. Mostly patient satisfy with their full denture, however some patients also unable to adapt to their full denture. Patient's dissatisfaction to denture is hard to understand because dentist's and patient's responses to denture are different. Patient probably dissatisfy to their denture appart from its quality. Patient's satisfaction to denture is the result that a dentist must achieve due to its relation to patient's quality of life. Patients often more prioritize the esthetic appearance of denture as their satisfaction factor. Ideal result of full denture depends on dentist's assesment to patient's need, doctor-patient relation, good communication, proper clinical technique, laboratory quality, patient's education, and maintenance after denture insertion.,

In partial denture, masticatory function, comfort, estethic, and retention become patient's satisfaction factors. Some patients satisfy to their partial denture if it's comfortable to wear and chew, while the others more prioritize the esthetic and retention. Once again, satisfaction assesment to denture between patient and doctor is different, and it can affect the relation between patient and dentist that affect the satisfaton to denture. It is important to remember that satisfaction to denture affects patient's quality of life. . $^{8-10}$

Previous studies have shown that many factors can play important role in patient's satisfaction to denture, including denture fabrication technique, patient's factor, and dentist's factor. Among these factors, there are five factors which show more effect to patient's satisfaction, including therapy selection, patient's personality and psychology, patient's oral hygiene, patient's perception about dentist and dental treatment, and communication. Given the different views to denture's result of patient and dentist, a good communication can increase satisfaction because patient can understand the quality and limitation of their denture and their expectation become more realistic. ${ }^{\text {? }}$

Clinician have a power to make a significant difference in patient's life. To get through the adaptation, patient must have partnership with clinician. Feeling that will give both positive and negative, depends on clinician's attitude and behaviour. This will affect patient's adaptation and acceptance to denture. $^{4}$

\section{Conclusion}

A dentist must recognize patient's mental attitude before their general health so the treatment could run well. According to House, there are four types of patient's mental attitude including philosophical, 
exacting, hysterical, and indifferent mind. However, reevaluation was made to House's classification which is shown by new classifications as expansion to House's classification including dentist's role to mental attitude. Moreover, dentist's attitude and good communication play important role to patient's attitude during treatment and patient's acceptance to denture.

\section{Acknowledgment}

The author would like to thank the advisor for this paper who has been support author to do the articles review.

\section{Conflict of Interest}

The authors report no conflict of interest.

\section{References}

1. Emami E, de-Souza RF, Kabawat M, et al. The impact of edentulism on oral and general health. Int J Dent 2013: 2-4

2. Choudhary S, Kumar A, Arora H. Correlation of patient's mental attitude with age, sex, and educational level: A survey. Eur J Dent 2016;10: 23, 26-28.

3. Gaikwad AV, Singh KP, Hazari P, Deshpande S, Babar G, Jain JK. Different classification systems of complete denture patients based on mental attitude: a review. IJOCR 2015;3: 28-31.
4. Bandodkar KA, Aras M. Psychological considerations for complete denture patients. J Indian Prosthodont Soc 2007;7: 71-73.

5. Gamer S, Tuch R, Garcia LTMM. House mental classification revisited: intersection of particular patient types and particular dentist's needs. J Prosthet Dent 2003;89: 297-298.

6. Nallaswamy D. Textbook of prosthodontic. 2nd Ed. New Delhi: Jaypee; 2017. p. 21.

7. Walia K, Belludi SA, Kulkarni P, et al. A comparative and a qualitative analysis of patient's motivation, expectation and satisfaction with dental implans. J Clin Diagn Res 2016; 10: 23 .

8. McCunniff M, Wei L, Dawson D, et al. Patients' esthetic expectation and satisfaction with complete dentures. J Prosthet Dent 2016: 2.

9. De-Siqueira GP, Dos-Santos MBF, Dos-Santos JFF, et al. Patients' expectation and satisfaction with removable dental prosthesis therapy and correlation with patients' evaluation of the dentists. Acta Odontol Scand 2013;71: 211.

10. Muchtar M, Habar ID. The speech ability on maxillary denture wearer: a systematic review. J Dentomaxillofac Sci 2018;3: 1-2.

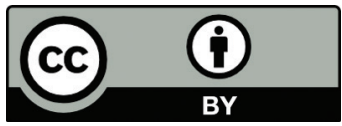

This work is licensed under a Creative Commons Attribution 